Bull. Mater. Sci., Vol. 21, No. 5, October 1998, pp. 399-402. (C Indian Academy of Sciences.

\title{
Loss of oxygen and carbon during donor formation in CZ-silicon
}

\author{
OM PRAKASH and SHYAM SINGH* \\ Department of Physics, G.B. Pant University of Agriculture and Technology, Pantnagar 263 145, India \\ MS received 10 July 1997; revised 18 April 1998
}

\begin{abstract}
Due to a lack of proper understanding about the formation mechanism of oxygen related donors during the transition temperature range $\left(465-540^{\circ} \mathrm{C}\right)$ which exhibits the transition of TDs to NDs, an attempt has been made to study their behaviour in the present context. We have found the formation and diffusion of molecule like oxygen at low temperature annealing of silicon and observed that second order kinetics of oxygen diffusion holds good. A relatively low value of $0.6 \mathrm{eV}$ has been estimated to be the activation energy for the diffusion of oxygen in silicon which is supposed to be due to the hydrogen passivation.
\end{abstract}

Keywords. Donors; kinetics; activation energy; oxygen precipitation; silicon.

\section{Introduction}

In view of the potential applications of the silicon, this material has been thoroughly investigated perhaps from all possible angles in order to optimize the material for device fabrication. Annealing of the oxygen rich silicon in the $300-500^{\circ} \mathrm{C}$ temperature range yields shallow donor states (Fuller et al 1954; Fuller and Logan 1957; Kaiser et al 1958), generally termed thermal donors. A lot of self-contradicting experimental data is available in the literature. Still there is a wide gap of doubt yet to be bridged up by a more methodical and comprehensive approach harmoniously blended with sound logic.

Annealing of the samples beyond $\approx 480^{\circ} \mathrm{C}$ results in the gradual disappearance of thermal donors and simultaneous appearance of a new kind of donors called new donors (NDs). However, behaviour of the oxygen related donors (ODs) in the transition temperature range (465$540^{\circ} \mathrm{C}$ ) which witnesses simultaneous existence of both TDs and NDs along with the possible presence of some thermal acceptors, is not yet well understood. Therefore, we have tried here to look at this important aspect.

Inherent presence of oxygen and carbon plays a crucial role in the formation mechanism of different donor species which differ from one another in their composition and electronic structure depending upon the temperature range within which they can be generated. On one hand a certain amount of oxygen is beneficial as it provides matrix hardening and also responsible for internal gettering effect; at the same time high concentration of oxygen in the sample leads to the degradation of device yield. Similarly the presence of carbon suppresses TD concentration while it enhances ND concentration. The question of formation and diffusion of molecule like

*Author for correspondence oxygen at low temperature in silicon has also been a point of debate for years together. Therefore, the present investigation is aimed to see the role and behaviour of oxygen and carbon in donor formation in $\mathrm{CZ}$-silicon in the temperature range $430-630^{\circ} \mathrm{C}$.

\section{Materials and methods}

Two types of CZ-silicon wafers were used in the study, henceforth referred to as group A and group B. The history of the samples has a great effect during the study of the annealed samples. Therefore, specifications and other information regarding the wafers are listed in table 1 as provided by the suppliers.

The wafers were as cut, etched and one side mirror polished. These wafers were cut down into small samples of dimension $1 \times 2 \mathrm{~cm}^{2}$ and heat treated for different schedules. In one schedule, group A samples were annealed for $26 \mathrm{~h}$ as a function of temperature between $465-540^{\circ} \mathrm{C}$ in regular steps. In the second schedule, groups A and B samples were pre-annealed for $24 \mathrm{~h}$ at $455^{\circ} \mathrm{C}$. After that, group A samples were heat treated at $470^{\circ} \mathrm{C}$ for $6-111 \mathrm{~h}$ in regular steps and group $\mathrm{A}+\mathrm{B}$ was given heat treatment for $11 \mathrm{~h}$ between $430-630^{\circ} \mathrm{C}$ in regular steps.

\subsection{Resistivity measurement and donor concentration}

Resistivity of silicon wafer was measured with a collinear four-probe array at room temperature and the number of carriers derived from Irvin's curve (Sze and Irvin 1968). After that, the wafer was heat treated and subsequently cleaned in hydrofluoric acid in order to eliminate the surface oxide. The resistivity of the annealed samples was again measured at room temperature and 
Table 1. History of the wafers.

\begin{tabular}{lcccccc}
\hline & & & & \multicolumn{2}{c}{$\begin{array}{c}\text { Initial concentrations } \\
\text { (ppma) }\end{array}$} \\
\hline Group & $\begin{array}{c}\text { Thickness } \\
(\mu \mathrm{m})\end{array}$ & Orientation & $\begin{array}{c}\text { Dia. } \\
(\mathrm{mm})\end{array}$ & $\begin{array}{c}\text { Resistivity } \\
(\mathrm{ohm}-\mathrm{cm})\end{array}$ & {$\left[\mathrm{C}_{\mathrm{s}}\right]$} & {$\left[\mathrm{O}_{\mathrm{i}}\right]$} \\
\hline A & $380-390$ & $\langle 100\rangle$ & 80.0 & $80-100$ & $11 \cdot 0$ & $37 \cdot 7$ \\
B & 210 & $\langle 100\rangle$ & $50 \cdot 0$ & $8-10$ & 8.4 & $22 \cdot 2$ \\
\hline
\end{tabular}

the corresponding number of charge carriers derived from the Irvin's curve. Assuming that the mobility remains constant, the difference of two carrier concentrations between unannealed and annealed samples gives the donors generated or annihilated during heat treatment.

\subsection{Precipitated oxygen and carbon}

Absorption coefficient needed to compute oxygen and carbon contents in the samples has been derived from $1106 \mathrm{~cm}^{-1}$ and $605 \mathrm{~cm}^{-1}$ bands, respectively, by FTIR measurements using the procedure laid down by lizuka et al (1985). The values of $\alpha_{0}$ (for oxygen) and $\alpha_{\mathrm{c}}$ (for carbon) so obtained helped to obtain the interstitial oxygen concentration $\left[\mathrm{O}_{\mathrm{i}}\right]$ and substitutional carbon concentration $\left[\mathrm{C}_{\mathrm{s}}\right]$ using the expressions:

$$
\begin{aligned}
& {\left[\mathrm{O}_{\mathrm{i}}\right]=\left(\begin{array}{ll}
3.03 & 0.02
\end{array}\right) \times 10^{17} \alpha_{\mathrm{o}} \mathrm{cm}^{-3},} \\
& {\left[\mathrm{C}_{\mathrm{s}}\right]=1.1 \times 10^{17} \alpha_{\mathrm{c}} \mathrm{cm}^{-3} .}
\end{aligned}
$$

The initial oxygen and carbon concentrations in the test wafer were measured without any treatment on it. Later, the wafer was given a specific heat treatment to calculate interstitial oxygen and substitutional carbon concentrations. The difference between the two is attributed to precipitated oxygen during heat treatment.

\section{Results and discussion}

\subsection{Donor activity in the temperature range $465-540^{\circ} \mathrm{C}$}

Annealing of the samples helped in reducing the inhomogeneities present in the unannealed samples up to a greater extent. The resistivity variation along with donor generation as a function of annealing temperature for $26 \mathrm{~h}$ of annealing had been observed for group A samples. As the group A sample is p-type, annealing for shorter duration $(\approx 1 \mathrm{~h})$ generally resulted in an increase of resistivity due to compensation mechanism and thereafter, resistivity fell-off indicating the reversal of the nature of the sample (Om Prakash et al 1998). In the present case donors generated at $465^{\circ} \mathrm{C}$ annealing for $26 \mathrm{~h}$ are $1.9 \times 10^{14} \mathrm{~cm}^{-3}$ with a maximum of $1.0 \times 10^{15} \mathrm{~cm}^{-3}$ at $480^{\circ} \mathrm{C}$. This behaviour is quite understandable as more and more oxygen atoms get clustered with silicon selfinterstitials $\mathrm{Si}_{\mathrm{I}}$ yielding electrically active donors. Annealing of the samples beyond $480^{\circ} \mathrm{C}$ and up to $510^{\circ} \mathrm{C}$ helped in the gradual disappearance of donor activity coming down to $2.6 \times 10^{14} \mathrm{~cm}^{-3}$. This is more likely due to joining of more oxygen atoms on the pre-existing TD rendering it electrically inactive. These inactive clusters get fragmented into smaller electrically active clusters i.e. NDs corresponding to $T>510^{\circ} \mathrm{C}$ annealing.

As a result of pre-annealing of the group B samples at $455^{\circ} \mathrm{C}$ for $24 \mathrm{~h}$ and subsequent annealing at $470^{\circ} \mathrm{C}$ for $6-111 \mathrm{~h}$ in regular steps, the resistivity decreases at first for annealing duration up to $54 \mathrm{~h}$. This is clearly a region where the TDs are under the process of generation and more and more TDs come into existence as electrically active clusters, a situation similar to that witnessed in the group A samples. The growth pattern of TDs (figure 1) coming up from $1.5 \times 10^{17} \mathrm{~cm}^{-3}$ for $6 \mathrm{~h}$ to $4.7 \times 10^{17} \mathrm{~cm}^{-3}$ for $54 \mathrm{~h}$ annealing assisted by the pre-annealing treatment is quite expected. This is contrary to the results reported earlier without pre-annealing where no saturation in donor concentration was observed (Tarun Kumar and Singh 1994; Om Prakash and Singh 1995). Beyond $54 \mathrm{~h}$ annealing duration the resistivity increases. This is a region where TDs are facing gradual extinction due to the formation of electrically inactive clusters.

\subsection{Donor activity in temperature range $430-630^{\circ} \mathrm{C}$}

Resistivity measurements on group $\mathrm{A}+\mathrm{B}$ samples revealed that initial region of the rapid growth of TDs has completely lost its entity due to the pre-annealing treatment, which advanced the TD generation process towards the lower annealing temperature. In our studies, annealing in the temperature range $430-630^{\circ} \mathrm{C}$ clearly indicated the presence of two OD regions: gradual disappearance of TDs and appearance of NDs. Simultaneous existence of thermal acceptors (TAs) along with new donors seems quite plausible. Figure 2 shows trend of the donors generated. The fact that the presence of carbon suppresses the TD formation and accelerates ND formation (Bean and Newman 1972), is clearly reflected herein from our data.

In this temperature range we conclude that: (i) TDs gradually disappear in the temperature range $430-510^{\circ} \mathrm{C}$ for group $\mathrm{A}$ and $430-470^{\circ} \mathrm{C}$ for group $\mathrm{B}$, (ii) NDs are 
formed in the temperature range $510-550^{\circ} \mathrm{C}$ for group $\mathrm{A}$ and $470-510^{\circ} \mathrm{C}$ for group $\mathrm{B}$, (iii) generation of more and more thermal acceptors as a function of annealing temperature compensates the ND concentration in both groups beyond $550^{\circ} \mathrm{C}$ and $510^{\circ} \mathrm{C}$, respectively and (iv) also the creation of recombination centres and ND like defects cannot be ruled out. Donor generation in group $\mathrm{A}$ is lower as compared to group $\mathrm{B}$ due to the presence of large amount of carbon, because carbon is known to be an efficient self-interstitial trap (Mathiot 1987).

\subsection{Oxygen diffusion at low temperatures $T<500^{\circ} \mathrm{C}$}

A smooth and gradual decrease in the values of absorption coefficients of oxygen as a function of annealing time has been noticed for groups $\mathrm{A}$ and $\mathrm{B}$ samples. We found that oxygen and carbon precipitation increases with increase in annealing temperature and duration as well (Cazcarra and Zunino 1980). In a crystal containing only interstitial oxygen atoms the first stage of oxygen aggregation has to be the formation of $\mathrm{O}_{2}$ dimers (McQuaid et al 1995). This is a second order process which is described by the equation:

$$
\frac{\mathrm{d}\left[\mathrm{O}_{\mathrm{i}}\right]}{\mathrm{d} t}=-8 \pi R R_{\mathrm{c}} D_{\mathrm{oxy}}\left[\mathrm{O}_{\mathrm{j}}\right]^{2},
$$

which, in turn, leads to

$$
\frac{1}{\left[\mathrm{O}_{\mathrm{i}}\right]_{\mathrm{t}}}-\frac{1}{\left[\mathrm{O}_{\mathrm{i}}\right]_{\mathrm{o}}}=8 \pi R_{\mathrm{c}} D_{\mathrm{oxy}} t
$$

where $R_{\mathrm{c}}$ is the capture radius associated with dimer formation and is expected to be $5 \AA$. A plot of difference of the reciprocal values of the actual oxygen concentration $\left[\mathrm{C}(t)^{-1}\right]$ and initial oxygen concentration $\left[\mathrm{C}(o)^{-1}\right]$ versus annealing time comes to be a straight line (figure 3 ) suggesting that the oxygen reduction can be described by a second order kinetics, as recently supported by McQuaid et al (1995). From the gradient of the straight line equal to $8 \pi R_{c} D_{v x y}$, the diffusion coefficient of the

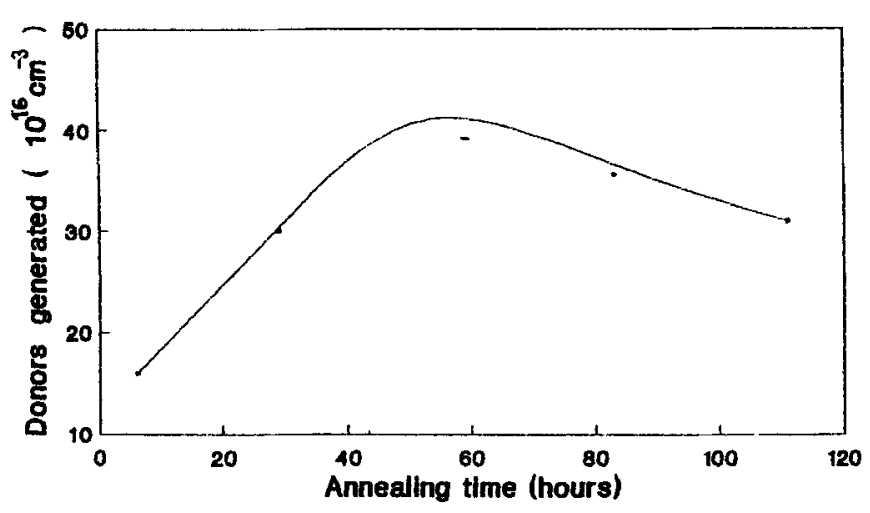

Figure 1. Donors generated as a function of annealing time at $450^{\circ} \mathrm{C}$, oxygen $\left(D_{\text {oxy }}\right)$, at temperature $470^{\circ} \mathrm{C}$ comes out to be $\approx 6.18 \times 10^{-19} \mathrm{~cm}^{2} \mathrm{~s}^{-1}$. The use of this procedure to analyse measurements relating to anneals at $450^{\circ} \mathrm{C}$ and $470^{\circ} \mathrm{C}$ led to normal values of $D_{\text {oxy }}$.

Arrhenius plot of the diffusion coefficient of oxygen as a function of $1 / k T$ is shown in figure 4 . From the slope of the line we found the activation energy for the normal diffusion of oxygen to be $\approx 0.6 \mathrm{eV}$, a value close to that reported by Gaworzewski and Schmalz (1980). This value is significantly lower than that estimated by Stavola et al (1983) which is $E_{\mathrm{a}}=2.54 \mathrm{eV}$. This lower value of $E_{\mathrm{a}}$ can be explained by sinks of diffusing $\mathrm{O}_{i}$ atoms. As grown $\mathrm{CZ}$-silicon may contain hydrogen impurities (Newman 1996) which could catalytically interact with neighbouring $O_{i}$ atoms and lower the energy of their saddle point configuration during the diffusion process. The activation energy for the diffusion of $\mathrm{Si}_{\mathrm{I}}$ atoms, $0.4 \mathrm{eV}$ (Gosele and Tan 1982), is quite comparable to the experimental value of oxygen diffusion estimated by our data. This leads one to conclude that the diffusion of oxygen at low temperatures is characteristic of the transport of self-interstitials chiefly due to the formation of molecule like oxygen clusters. In this process the dimer dissociation rate has been neglected in comparison to dimer formation rate. These dimers having small binding energy $(0.1-1.0 \mathrm{eV})$ diffuse more easily in silicon lattice because dimers have small activation energy $(1.4 \mathrm{eV})$ than single $\mathrm{O}_{\mathrm{i}}$ atoms.

In our quantitative analysis we found an average of seven oxygen atoms involved in a single donor formation at low temperatures. For this purpose we took a group of $\mathrm{Si}$ samples having negligibly less carbon impurities to avoid the other complex formation like $\mathrm{C}-\mathrm{O}$, rather than oxygen related defects during the heat treatment at different temperatures. By comparison between the number of maximum donors generated and the amount of oxygen reduced at different temperatures $\left(450^{\circ} \mathrm{C}<T<500^{\circ} \mathrm{C}\right)$, we found that it takes an average of seven oxygen atoms for a single donor formation.

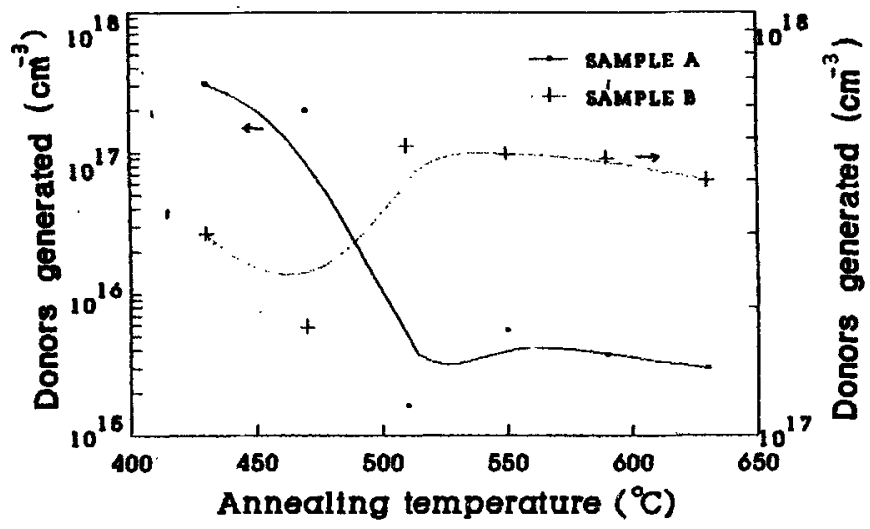

Figure 2. Variation of donors generated as a function of temperature annealed for $11 \mathrm{~h}$. 


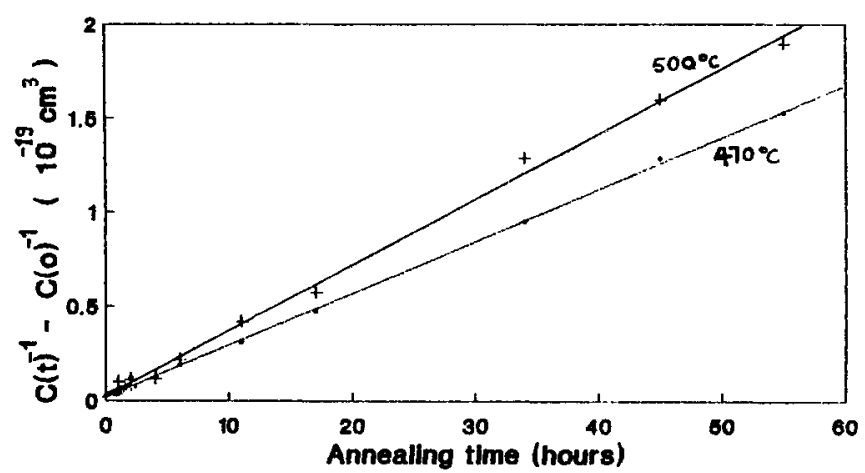

Figure 3. Plot of differences of reciprocal values of oxygen concentration at time $t$ and initial oxygen concentration $\left[\mathrm{C}(t)^{-1}-\right.$ $\left.\mathrm{C}(\mathrm{o})^{-1}\right]$ as a function of annealing time at $470^{\circ} \mathrm{C}$ and $500^{\circ} \mathrm{C}$.

\subsection{Role of carbon during donor formation}

3.4a Suppression effect of TD formation: At low temperature $\left(T<500^{\circ} \mathrm{C}\right)$ the normal TD annihilation unrelated to carbon has generally been described to further the growth of TD clusters beyond the critical size to induce the change of TD structure to lose its electrical activity (Wagner and Hage 1989). In the present study, carbon induced the gradual disappearance of TDs and carbon itself at $470^{\circ} \mathrm{C}$ of annealing. However, neither carbon can move at $470^{\circ} \mathrm{C}$ as long as it occupies a substitutional site $\left(\mathrm{C}_{s}\right)$, nor $\mathrm{TDs}$ can. It has been proposed that $\mathrm{Si}_{1}$ atoms may play a role in the formation and electrical activity of TDs (Newman 1985). Therefore, we propose the hypothesis that $\mathrm{Si}_{\mathrm{I}}$ created during oxygen aggregation process $\left(\mathrm{O}_{2}\right.$ formation) ejects $\mathrm{C}_{\mathrm{s}}$ into an interstitial site $\mathrm{C}_{\mathrm{i}}$. This $\mathrm{C}_{1}$ rapidly diffuses to various species of TDs to interact them so as to make them electrically inactive. However, exact mechanism of this process is not yet known. The main problem with this explanation is that calculations (Kelly 1989) indicate that there is insufficient strain within a cluster as small as $\mathrm{O}_{2}$ to cause the ejection of a $\mathrm{Si}_{\mathrm{r}}$.

3.4b Enhancement effect on ND formation: It has been found that presence of carbon leads to the enhancement of new donor formation at higher temperature range $\left(T>550^{\circ} \mathrm{C}\right)$. Carbon has been recognized to provide nucleation sites for oxygen precipitation around $650^{\circ} \mathrm{C}$ (Gaworzewski and Schmalz 1983). The present results obtained by us have suggested that NDs are carbon related. The resistivity measurements have clearly indicated that both low temperature pre-annealing and carbon enhance the ND generation.

In general, as to the oxygen reduction samples preannealed at $455^{\circ} \mathrm{C}$ and not pre-annealed behave similarly. The absolute values, however, are different in preannealed samples. The oxygen reduction starts only after

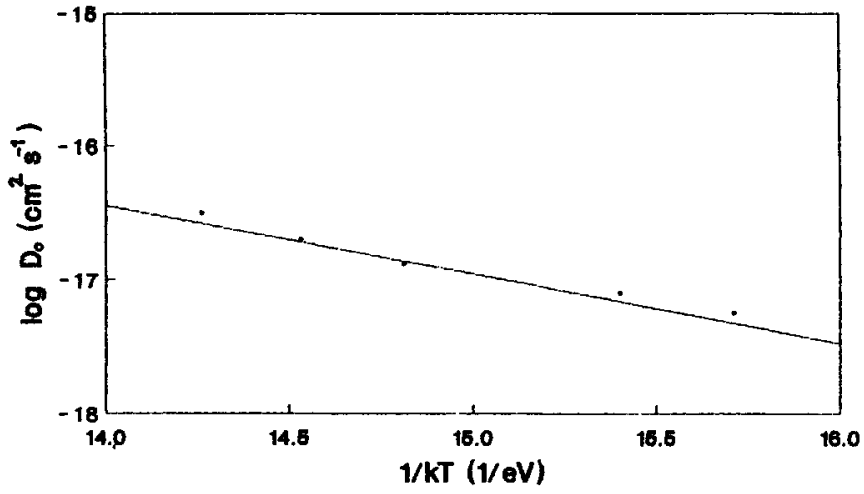

Figure 4. Arrhenius plot of oxygen diffusion coefficient as a function of $1 / k T$.

annealing for $6 \mathrm{~h}$ at $630^{\circ} \mathrm{C}$ where the annihilation of TDs is finished and the formation of NDs has begun.

\section{Acknowledgements}

We express our sincere thanks to Drs Rajendra Kumar, D R Sagar and B B Sharma, Solid State Physics Laboratory, Delhi and Dr N K Upreti, IWST, Bangalore for their help in experimental work.

\section{References}

Bean A R and Newman R C 1972 J. Phys. Chem. Solids 33 255

Cazcarra V and Zunino P $1980 \mathrm{~J}$. Appl. Phys. 51206

Fuller C S and Logan R A 1957 J. Appl. Phys. 281427

Fuller C S, Ditzenberger J A, Hanny N B and Buehler E E 1954 J. Appl. Phys. 96833

Gaworzewski P and Schmalz K 1980 Phys. Status Solidi (a) 58 K223

Gaworzewski P and Schmalz K 1983 Phys. Status Solidi (a) 77571

Gosele U and Tan T Y 1982 Appl. Phys. A28 79

lizuka T, Takasu S, Tajima M, Arai T, Nozaki T, Inoue $\mathrm{N}$ and Watanake M 1985 J. Electrochem. Soc. 1321707

Kaiser W, Frisch H L and Reiss H 1958 Phys. Rev. 1121546

Kelly P J 1989 Mater. Sci. Forum 38-41 269

Mathiot D 1987 Appl. Phys. Lett. 51904

McQuaid S A, Binns M J, Londos C A, Tucker J H, Brown A R and Newman R C 1995 J. Appl. Phys. 771427

Newman R C 1985 J. Phys. C18 L967

Newman R C 1996 Mater. Sci. \& Engg. B36 1

Om Prakash and Singh S 1995 Indian J. Phys. A69 509

Om Prakash, Upreti N K and Singh S 1998 Mater. Sci. \& Engg. B52 180

Stavola M, Patel J R, Kimmerling L C and Freeland P E 1983 Appl. Phys. Lett. 4273

Sze S M and Irvin J C 1968 Solid State Electronics 11599

Tarun Kumar and Singh S 1994 Bull. Electrochem. 10518

Wagner P and Hage J 1989 Appl. Phys. A49 123 